\title{
Atividade Potencialmente Alelopática de Extratos Brutos e HidROALCOÓlicos de FEIJ ÃO-DE-PORCO (Canavalia ensiformis) ${ }^{1}$
}

\author{
Potential Allelopathic Activity in Hydroalcoholic and Raw Extracts of Canavalia ensiformis
}

\author{
SOUZA FILHO, A.P.S. ${ }^{2}$
}

\begin{abstract}
RESUMO - Extratos hidroalcoólicos de parte aérea, raízes e sementes e extratos brutos de sementes de Canavalia ensiformis foram preparados, visando identificar e caracterizar os efeitos potencialmente alelopáticos sobre a germinação de sementes e o alongamento da radícula das plantas daninhas Mimosa pudica, Urena lobata, Senna obtusifolia e Senna occidentalis. Os trabalhos foram desenvolvidos em condições controladas de $25{ }^{\circ} \mathrm{C}$ de temperatura e fotoperíodo de 12 horas, para o bioensaio de germinação, e 24 horas, para o de alongamento da radícula. Os efeitos foram aquilatados tendo por contraste (testemunha) a água destilada. Os resultados variaram em função da espécie receptora, da concentração e da parte da planta utilizada no preparo dos extratos. A inibição da germinação das sementes e do alongamento da radícula foi diretamente proporcional à concentração do extrato, com as mais intensas inibições observadas na concentração de 4\%. Independentemente da espécie receptora, as sementes, seguidas das raízes, foram as principais fontes de substâncias químicas com atividades potencialmente alelopáticas no feijão-de-porco. A análise dos diferentes extratos brutos revelou que as substâncias químicas com atividades potencialmente alelopáticas presentes nas sementes do feijão-de-porco têm polaridade compreendida entre o acetato de etila e o metanol. Para o extrato bruto metanólico, concentrações a partir de 0,4\% inibiram completamente a germinação das espécies receptoras, enquanto para M. pudica e S. occidentalis concentrações de 0,6 e 0,8\% proporcionaram inibições da ordem de $100 \%$ para a germinação das sementes dessas espécies. A sensibilidade das espécies aos efeitos potencialmente alelopáticos variou na seguinte ordem decrescente: $M$. pudica $>$ S. occidentalis $>$ S. obtusifolia > U. lobata.
\end{abstract}

Palavras-chave: alelopatia, germinação, inibição, planta daninha, radícula, semente.

ABSTRACT - Hydroalcoholic extracts from shoot, roots and seeds and seed raw extracts from Canavalia ensiformis were prepared to identify and characterize their potential allelopathic effects on seed germination and radicle elongation of the weeds Mimosa pudica, Urena lobata, Senna obtusifolia, and Senna occidentalis. The germination bioassay was carried out at $25{ }^{\circ} \mathrm{C}$ and a 12-hour photoperiod, and the radicle elongation bioassay at $25^{\circ} \mathrm{C}$ and a 24-hour photoperiod. Distilled water was used as the control treatment. The effects varied according to the receiving species, concentration and part of the donor plant. Germination and radicle elongation inhibition were directly proportional to the concentration of the extract, with the most active inhibition being observed at the concentration of $4.0 \%$. Regardless of the receiving species, seeds and roots were the main source of compounds with allelopathic activities. The analysis of different raw extracts showed that the compounds with potential allelopathic activity have polarity between ethyl acetate and methanol. For the raw methanol extract, concentration higher than $0.4 \%$ had a completely inhibitory effect on the seed germination of the receiving species, with 0.6 and 0.8 concentrations being also inhibitory for $\boldsymbol{M}$. pudica and $\mathbf{S}$. occidentalis germination. The sensitivity of the receiving species varied in the following decreasing order: M. pudica > S. occidentalis $>$ S. obtusifolia $>$ U. lobata.

Key words: allelopathy, germination, inhibition, weed, radicle, seed.

Recebido para publicação em 15/4/2002 e na forma revisada em 9/12/2002.

Embrapa Amazônia Oriental, Trav. Dr. Enéas Pinheiro, S/N, 66095-100 Belém-Pará, <apedro@cpatu.embrapa.br>. 


\section{INTRODUÇÃO}

O aparecimento e o desaparecimento de espécies de plantas, bem como as constantes flutuações na densidade e dominância de determinadas espécies em ecossistemas cultivados, como é o caso das pastagens, têm sido atribuídos a diferentes fatores, como à competição por componentes ambientais essenciais à sobrevivência das espécies (Putnam \& Tang, 1986). Nas últimas três décadas, entretanto, vários trabalhos vêm mostrando que a alelopatia, efeito direto e indireto de uma planta sobre outra, através da produção e liberação de substâncias químicas com atividade fitotóxica, tem participação decisiva na dinâmica populacional das plantas no campo, alterando o padrão e a densidade da vegetação (Smith, 1989). Conquanto o conceito cunhado por Molisch, em 1937, envolva tanto os efeitos benéficos como os deletérios (Rice, 1979), e este último tem sido mais comumente documentado do que o primeiro.

A alelopatia pode representar excelente alternativa estratégia de manejo das pastagens, por meio da seleção de espécies forrageiras, como as leguminosas, cujo nível de atividade alelopática possibilite o controle da infestação da pastagem por plantas indesejáveis. A principal conseqüência dessa estratégia seria a obtenção de estandes mais puros, mais densos e mais produtivos, redundando, positivamente, no aumento da longevidade produtiva da pastagem (Souza Filho \& Alves, 1998). Esse fenômeno tem importância ecológica, notadamente em função da possibilidade de fornecer fontes alternativas de novas estruturas químicas com possibilidade para produção de biodefensivos agrícolas.

No contexto do manejo das pastagens, a identificação de espécies de leguminosas forrageiras e de gramíneas com propriedades alelopáticas contra as plantas daninhas é passo inicial na exploração desse fenômeno. Nesse sentido, vários trabalhos que procuram identificar potencialidades alelopáticas em leguminosas forrageiras foram desenvolvidos em passado recente, como é o caso daqueles desenvolvidos com Pueraria phaseoloides, Leucaena leucocephala, Stylosanthes guianensis e outras (Souza Filho \& Alves, 2000; Souza Filho et al., 1997; Tawata \& Hongo,
1987). Com relação ao feijão-de-porco, Magalhães \& Franco (1962) observaram que plantas de tiririca, quando submetidas ao tratamento com extrato de nódulos de raízes de feijão-de-porco (Canavalia ensiformis), evidenciaram inibição do brotamento dos tubérculos e folhas cloróticas. Anaya (1999) constatou que folhas de feijão-de-porco, quando adicionadas ao solo, reduzem em mais de 50\% o índice de incidência de nematóides de raízes em tomateiros. O desenvolvimento de estudos visando identificar a possibilidade de o feijão-de-porco ter potencial alelopático para inibir a germinação de sementes e o alongamento da radícula de outras plantas invasoras, bem como a principal fonte de substâncias alelopáticas, é de suma importância na avaliação das reais potencialidades dessa leguminosa forrageira. Este trabalho teve por objetivo identificar e caracterizar a atividade potencialmente alelopática do feijão-de-porco.

\section{MATERIAL E MÉTODOS}

\section{Obtenção do material}

O feijão-de-porco (Canavalia ensiformis) foi cultivado em solo Latossolo Amarelo, sem o emprego de adubação, no Campo Experimental da Embrapa Amazônia Oriental, localizado em Belém-PA. O clima local é do tipo Afi, tropical chuvoso, com período de máxima precipitação compreendido entre os meses de dezembro e julho. A temperatura média anual é de $26^{\circ} \mathrm{C}$, com temperatura mínima média de $22,9^{\circ} \mathrm{C}$ e máxima de $31,8^{\circ} \mathrm{C}$, pluviosidade média anual de $3.000 \mathrm{~mm}$ e umidade relativa média de $84 \%$ (Laboratório de Climatologia da Embrapa Amazônia Oriental, Belém-PA - média de 30 anos). A semeadura foi realizada em fins do mês de fevereiro e a colheita do material, em maio. Após esse período, as plantas foram arrancadas e separadas em parte aérea (folhas + colmos) e raízes. O material foi seco em estufa com circulação de ar forçada, por 96 horas, à temperatura constante de $39{ }^{\circ} \mathrm{C}$. Posteriormente, foi triturado em moinho tipo Willey e acondicionado em sacos de plástico. As sementes foram obtidas de um plantio da Embrapa Amazônia Oriental, em Belém-PA, e passaram pelos mesmos processos relativos à secagem e trituração empregados para as outras frações da planta. 


\section{Espécies receptoras}

Como plantas receptoras, foram utilizadas, nos bioensaios envolvendo o extrato hidroalcoólico, duas das principais plantas daninhas que ocorrem em áreas de pastagens cultivadas da Região Amazônica, que são a malícia (Mimosa pudica Mill) e a malva (Urena lobata). Na avaliação dos extratos brutos foram incluídas mais duas espécies de plantas daninhas, também com larga ocorrência nas áreas de pastagens: mata-pasto (Senna obtusifolia) e fedegoso (Senna occidentalis). As sementes dessas duas invasoras foram coletadas no municipio de Castanhal-PA. Passaram por processo de limpeza e expurgo e foram acondicionadas em câmaras de conservação de sementes. A dormência das sementes foi superada conforme estabelecido por Souza Filho et al. (1998).

\section{Preparo dos extratos hidroalcoólicos}

Partindo-se de 2,0 kg de material seco de cada uma das partes da planta (parte aérea, sementes e raízes), procedeu-se à extração exaustiva com solução hidroalcoólica na proporção de 1:7:3 (material seco: etanol: água) por 15 dias consecutivos para cada fração da planta, à temperatura ambiente. Após evaporação do etanol em rotaevaporador, realizouse a liofilização do material, o qual foi utilizado para preparar os extratos hidroalcoólicos nas concentrações de $0,1,2$ e $4 \%$.

\section{Preparo dos extratos brutos}

Na Figura 1 são apresentados os procedimentos utilizados na separação das substâncias químicas presentes nas sementes do feijão-deporco, responsáveis pelas atividades potencialmente alelopáticas, em função da polaridade. Utilizaram-se as sementes em face dos excelentes resultados verificados nos bioensaios, em que se avaliaram as diferentes partes dessa planta forrageira. Os procedimentos envolveram a utilização, em seqüência, de solventes com polaridade crescente, partindo-se de $5,0 \mathrm{~kg}$ de sementes secas trituradas. Assim, os solventes foram utilizados na seguinte ordem: hexano, diclorometano, acetato de etila, metanol e água. Cada extração foi realizada por 20 dias seguidos, em condições ambientais. Após cada extração, processava-se a concen- tração em rotaevaporador. Os procedimentos utilizados foram aqueles propostos por Heisey (1996). A avaliação da atividade biológica desses extratos foi realizada na concentração de $1 \%$. Tendo em vista os efeitos promovidos pelo extrato bruto metanólico (EBMET) das sementes, avaliaram-se diferentes concentrações deste no intervalo de 0,0 a 0,8\%.

\section{Procedimentos experimentais}

Os bioensaios de germinação foram desenvolvidos em condições controladas de $25^{\circ} \mathrm{C}$ de temperatura constante e fotoperíodo de 12 horas. A germinação foi monitorada em períodos de 15 dias, com contagens diárias e eliminação das sementes germinadas. Foram consideradas sementes germinadas aquelas que apresentavam extensão radicular igual ou superior a 2,00 mm (Juntila, 1976; Duram \& Tortosa, 1985). Cada placa de Petri transparente, de 9,0 cm de diâmetro, recebeu 20 sementes.

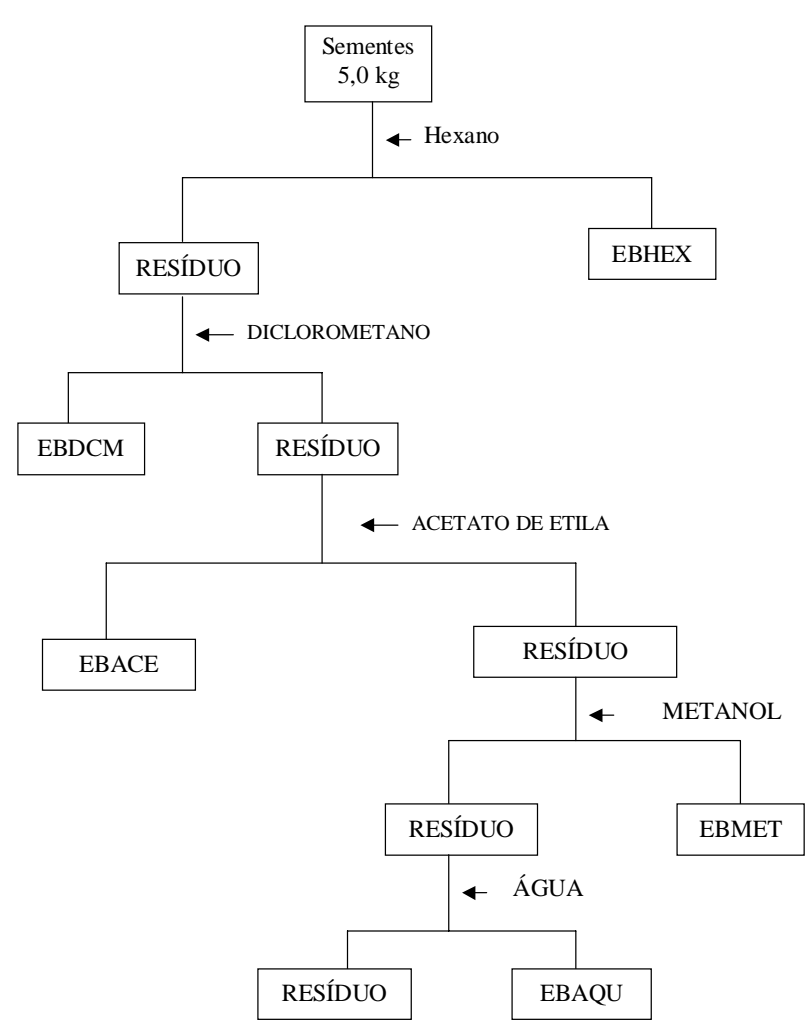

Figura 1 - Procedimentos de partição das substâncias químicas com atividades potencialmente alelopáticas presentes nas sementes do feijão-de-porco.

Planta Daninha, Viçosa-MG, v.20, n.3, p.357-364, 2002 
Os bioensaios de alongamento da radícula foram realizados em condições controladas de $25{ }^{\circ} \mathrm{C}$ de temperatura constante e fotoperíodo de 24 horas. Foram utilizadas seis sementes prégerminadas, por aproximadamente três dias, por placa de Petri transparente de $9,0 \mathrm{~cm}$ de diâmetro. Ao final de um período de 10 dias de crescimento, mediu-se o comprimento das radículas.

Cada placa de Petri, forrada com uma folha de papel-filtro qualitativo, recebeu $3,0 \mathrm{ml}$ de extrato, com igual volume para o tratamento considerado testemunha: água destilada. Após a evaporação da parte alcoólica, em condições ambientais, adicionou-se o volume equivalente do etanol evaporado $(2,1 \mathrm{~mL})$ com água destilada, mantendo-se, dessa maneira, o volume original de 3,0 mL e as concentrações dos extratos. No caso da avaliação dos extratos brutos, os procedimentos foram os mesmos, com exceção da concentração, que foi de 1\%, e do volume de água reposto, de 3,0 mL. Os extratos foram adicionados apenas quando do início de cada bioensaio, sendo adicionada, a partir de então, apenas água destilada, quando necessário.

\section{Análise estatística}

O delineamento experimental para todos os bioensaios foi o inteiramente casualizado, com três repetições. Os dados foram submetidos à análise de variância pelo teste $\mathrm{F}$ e as médias comparadas pelo teste de Tukey $(\mathrm{P}<5 \%)$. Todas as análises foram realizadas no programa SAS (Sas, 1989).

\section{RESULTADOS E DISCUSSÃO}

\section{Efeitos de extratos hidroalcoólicos sobre a germinação das sementes}

A germinação das sementes das plantas daninhas malícia e malva variou $(p<0,05) \mathrm{em}$ função da concentração e da parte da planta doadora utilizada no preparo dos extratos. Independentemente da parte da planta de feijão-de-porco utilizada e da planta receptora, a inibição foi sempre crescente com o aumento da concentração do extrato, sendo na concentração de $4 \%$ observadas as inibições mais intensas (Tabela 1).

Comparativamente, o extrato hidroalcoólico preparado a partir de sementes tendeu a proporcionar inibições mais intensas na germinação das sementes (Tabela 1). Essa superioridade foi mais marcante na concentração de $1 \%$, em que o extrato de sementes causou inibição da ordem de $61,0 \%$ na espécie malícia e de 39,0\% na malva, enquanto os extratos de raízes e da parte aérea efetivaram inibições da ordem de 23,0 e $7,0 \%$ e 20,0 e $5,0 \%$, respectivamente para malícia e malva. No entanto, na concentração de $2 \%$, os extratos de sementes e de raízes provocaram inibições equivalentes ( $>00,05)$, mas superiores $(p<0,05)$ ao extrato da parte aérea. Na concentração de $4 \%$, não houve diferenças $(p>0,05)$ nas inibições efetivadas pelos extratos preparados a partir das diferentes partes do feijão-de-porco, tanto para malícia como para malva. Aparentemente, a $1 \%$, a concentração das substâncias químicas com atividade potencialmente alelopática presentes na parte aérea do feijão-de-porco estava abaixo daquela exigida para inibir a germinação das sementes das espécies invasoras, o que não aconteceu para sementes e raízes. Na concentração de $2 \%$, a concentração de aleloquímicos na parte aérea do feijão-de-porco foi suficiente para reduzir a germinação em $68,0 \%$ (malícia) e 46,0\% (malva), porém, conquanto esses valores possam ser considerados expressivos, ainda assim foram inferiores $(\mathrm{p}<0,05)$ àqueles observados nos extratos de sementes e raizes (Tabela 1). Esses resultados parecem indicar que as sementes, em primeiro lugar, e as raízes, em segundo lugar, se constituem nas principais fontes de substâncias químicas com atividades alelopáticas presentes no feijão-deporco.

\section{Efeitos de extratos hidroalcoólicos sobre o alongamento da radícula}

À semelhança dos efeitos observados sobre a germinação das sementes, o alongamento da radícula também variou $(\mathrm{p}<0,05)$ em função da concentração e da parte da planta doadora utilizada no preparo dos extratos (Tabela 2). As reduções foram sempre crescentes com o aumento da concentração, sendo as mais intensas na concentração de 4\%. Na concentração de $1 \%$, foram observadas reduções da ordem de $38,0,48,0$ e $62,0 \%$ no alongamento da radícula da espécie malícia e de 54,0, 78,0 e 64,0\% na espécie malva, respectivamente pelos extratos de parte aérea, sementes e raízes (Tabela 2). 
Tabela 1 - Efeitos de extratos hidroalcoólicos de feijão-de-porco na germinação de duas espécies de plantas invasoras. Dados expressos em percentuais de inibição, em relação ao tratamento testemunha

\begin{tabular}{|c|l|c|c|c|}
\hline \multirow{2}{*}{ Espécie receptora } & \multirow{2}{*}{ Parte da planta doadora } & \multicolumn{3}{|c|}{ Concentração do extrato (\%) } \\
\cline { 3 - 5 } & & 1 & 2 & 4 \\
\hline \multirow{3}{*}{ Malícia } & Parte aérea & $7,0 \mathrm{Cc}$ & $68,0 \mathrm{Bb}$ & $89,0 \mathrm{Aa}$ \\
& Sementes & $61,0 \mathrm{Ac}$ & $78,0 \mathrm{Ab}$ & $90,0 \mathrm{Aa}$ \\
& Raízes & $23,0 \mathrm{Bc}$ & $77,0 \mathrm{Ab}$ & $90,0 \mathrm{Aa}$ \\
\hline \multirow{3}{*}{ Malva } & Parte aérea & $5,0 \mathrm{Cc}$ & $46,0 \mathrm{Bb}$ & $89,0 \mathrm{Aa}$ \\
& Sementes & $39,0 \mathrm{Ac}$ & $69,0 \mathrm{Ab}$ & $91,0 \mathrm{Aa}$ \\
& Raízes & $20,0 \mathrm{Bc}$ & $68,0 \mathrm{Ab}$ & $90,0 \mathrm{Aa}$ \\
\hline
\end{tabular}

Médias seguidas de letras iguais, maiúsculas na coluna e minúsculas na linha, dentro de cada espécie receptora, não diferem pelo teste de Tukey $(\mathrm{p}>0,05)$.

Tabela 2 - Efeitos de extratos hidroalcoólicos de feijão-de-porco no alongamento da radícula de duas espécies de plantas invasoras. Dados expressos em percentuais de inibição em relação ao tratamento testemunha

\begin{tabular}{|c|l|c|c|c|}
\hline \multirow{2}{*}{ Espécie receptora } & \multirow{2}{*}{ Parte da planta doadora } & \multicolumn{3}{|c|}{ Concentração do extrato (\%) } \\
\cline { 3 - 5 } & & 1 & 2 & 4 \\
\hline \multirow{3}{*}{ Malícia } & Parte aérea & $38,0 \mathrm{Cc}$ & $62,0 \mathrm{Bb}$ & $77,0 \mathrm{Ba}$ \\
& Sementes & $48,0 \mathrm{Bc}$ & $56,0 \mathrm{Cb}$ & $67,0 \mathrm{Ca}$ \\
& Raízes & $62,0 \mathrm{Ab}$ & $88,0 \mathrm{Aa}$ & $91,0 \mathrm{Aa}$ \\
\hline \multirow{3}{*}{ Malva } & Parte aérea & $54,0 \mathrm{Cc}$ & $86,0 \mathrm{Ab}$ & $93,0 \mathrm{Aa}$ \\
& Sementes & $78,0 \mathrm{Aa}$ & $87,0 \mathrm{Ab}$ & $93,0 \mathrm{Aa}$ \\
& Raízes & $64,0 \mathrm{Bc}$ & $85,0 \mathrm{Ab}$ & $92,0 \mathrm{Aa}$ \\
\hline
\end{tabular}

Médias seguidas de letras iguais, maiúsculas na coluna e minúsculas na linha, dentro de cada espécie receptora, não diferem pelo teste de Tukey $(\mathrm{p}>0,05)$.

A análise comparativa dos efeitos promovidos pelas diferentes fontes de extratos revelou que os extratos preparados a partir de raízes e sementes foram os que efetivaram as reduções mais intensas $(\mathrm{p}<0,05)$ no alongamento da radícula, particularmente na concentração de $1 \%$ (Tabela 2). Ao contrário dos efeitos observados na germinação das sementes (Tabela 1), em que o extrato preparado da parte aérea do feijãode-porco praticamente não afetou a germinação das sementes na concentração de $1 \%$, foram observadas, nessa concentração, reduções da ordem de 38,0\% no alongamento da radícula da invasora malícia e de 54,0\% no alongamento da radícula da malva (Tabela 2). Aparentemente, na concentração de $1 \%$, o nível das substâncias químicas com atividade alelopática presentes na parte aérea do feijão-de-porco estava abaixo daquele exigido para inibir de forma expressiva a germinação das sementes da malícia, porém suficiente para inibir o desenvolvimento da radícula das duas espécies de plantas receptoras.
As inibições médias promovidas nas concentrações de 1 e $2 \%$, no bioensaio de alongamento da radícula, confirmam as raízes e as sementes com as principais fontes de substâncias químicas com atividade alelopática presentes no feijão-de-porco. Paralelamente, as inibições médias de $61,11 \%$ na germinação das sementes e de $73,0 \%$ no alongamento da radícula, independentemente da planta doadora e da concentração dos extratos, mostram que o alongamento da radícula foi mais intensamente afetado pelas substâncias químicas com atividades alelopáticas do que a germinação das sementes.

O grau de inibição proporcionado por determinado aleloquímico é dependente da sua concentração (Harper \& Balke, 1981). Segundo Rice (1984), quando em baixas concentrações, as substâncias alelopáticas podem não ser inibitórias para determinadas espécies ou até mesmo apresentar efeitos estimulatórios, ao passo que em altas concentrações as substâncias são completamente inibitórias. A concentração máxima de 4\% utilizada neste trabalho, 
entretanto, está abaixo daquela preconizada por Stowe (1979) para esse tipo de avaliação, que é de 5\%. Dessa forma, os resultados obtidos podem ser considerados extremamente positivos e qualificam o feijão-de-porco como fonte alternativa de novas substâncias químicas, com potencial para desenvolver estudos mais avançados com vistas à produção de biodefensivos agrícolas.

As intensas inibições efetivadas tanto na germinação das sementes como no alongamento da radícula das duas espécies de plantas invasoras assumem aspectos ecológicos importantes quando se considera a alelopatia como ferramenta estratégica de manejo das pastagens cultivadas consorciadas. Os efeitos sobre a germinação podem refletir diretamente na densidade e abundância das plantas invasoras, reduzindo-lhes a competitividade. No entanto, os efeitos no alongamento da radícula também afetam a capacidade competitiva das invasoras por fatores essenciais à sobrevivência, como água e nutrientes. A principal conseqüência desses dois aspectos é o aumento da produtividade e longevidade da pastagem, com reflexos positivos na redução dos custos de manutenção da pastagem.

\section{Efeitos dos extratos brutos sobre a germi- nação de sementes}

Os efeitos proporcionados pelos diferentes extratos brutos obtidos de sementes do feijãode-porco são apresentados na Tabela 3. Levando-se em conta que os resultados refletem o potencial inibitório das substâncias químicas aglutinadas em função de suas polaridades, verifica-se que as substâncias químicas presentes nos extratos brutos hexânico (EBHEX), diclorometânico (EBDCM) e aquoso (EBAQU) evidenciaram baixas atividades inibitórias.
Inibições expressivas foram verificadas para os efeitos dos extratos brutos acetato de etila (EBACE), que promoveu inibições variando de 71 a 89\%, e metanólico (EBMET), em que inibições da ordem de 85 a 100\% foram observadas (Tabela 3). Esses resultados indicam que a maior concentração das substâncias químicas com atividade alelopática, presentes nas sementes de feijão-de-porco, em relação à polaridade, está compreendida entre o acetato de etila e o metanol.

Tendo em vista que o extrato bruto metanólico (EBMET) foi aquele que produziu as inibições mais intensas na germinação das sementes, prepararam-se diferentes concentrações desse extrato - 0,0; 0,$2 ; 0,4 ; 0,6$; e 0,8\% - visando quantificar a extensão de inibição para concentrações inferiores àquela utilizada na avaliação dos extratos brutos, que foi de $1,0 \%$. Os resultados apresentados na Tabela 4 mostram que a intensidade dos efeitos potencialmente alelopáticos variou $(p<0,05)$ em função da concentração do extrato e da espécie receptora. Efetivamente, as informações disponiveis deixam claro que a intensidade dos efeitos dos aleloquímicos é dependente da concentração (Reigosa et al., 1999; Abrahim et al., 2000; Kato-Noguchi et al., 1994).

Tabela 4 - Efeitos da concentração do extrato bruto metanólico preparado a partir de sementes de feijão-deporco na germinação de sementes de plantas invasoras. Dados expressos em percentual de inibição em relação ao tratamento testemunha (água destilada)

\begin{tabular}{|l|r|c|r|r|}
\hline \multirow{2}{*}{$\begin{array}{c}\text { Planta } \\
\text { receptora }\end{array}$} & \multicolumn{4}{|c|}{ Concentração (\%) } \\
\cline { 2 - 5 } & \multicolumn{1}{|c|}{0,2} & 0,4 & \multicolumn{1}{c|}{0,6} & \multicolumn{1}{c|}{0,8} \\
\hline Mata-pasto & $3,22 \mathrm{Cd}$ & $20,0 \mathrm{Cc}$ & $45,48 \mathrm{Cb}$ & $66,98 \mathrm{Ba}$ \\
Malícia & $15,22 \mathrm{Ac}$ & $60,87 \mathrm{Ab}$ & $100,00 \mathrm{Aa}$ & $100,00 \mathrm{Aa}$ \\
Fedegoso & $8,89 \mathrm{Bd}$ & $48,88 \mathrm{Bc}$ & $77,78 \mathrm{Bb}$ & $100,00 \mathrm{Aa}$ \\
Malva & $5,27 \mathrm{Cd}$ & $13,98 \mathrm{Dc}$ & $30,52 \mathrm{Db}$ & $52,10 \mathrm{Ca}$ \\
\hline
\end{tabular}

Médias seguidas de letras iguais, maiúsculas na coluna e minúsculas na linha, não diferem pelo teste de Tukey $(0,05)$.

Tabela 3 - Efeitos de extratos brutos de sementes de feijão-de-porco na germinação de sementes de plantas invasoras. Dados expressos em percentual de inibição em relação ao tratamento considerado testemunha (água destilada)

\begin{tabular}{|l|c|c|c|r|r|}
\hline \multirow{2}{*}{ Planta receptora } & \multicolumn{5}{|c|}{ Extrato bruto } \\
\cline { 2 - 6 } & EBHEX & EBDCM & EBACE & EBMET & EBAQU \\
\hline Malva & 3,15 & 4,12 & 77,32 & 90,10 & 7,22 \\
Mata-pasto & 2,10 & 1,08 & 71,68 & 85,00 & 1,08 \\
Malícia & 5,10 & 18,48 & 89,10 & 100,00 & 11,39 \\
Fedegoso & 3,30 & 2,20 & 77,15 & 100,00 & 13,86 \\
\hline
\end{tabular}


Individualmente, as espécies de plantas invasoras responderam $(\mathrm{p}<0,05)$ diferentemente às variações na concentração do extrato na faixa considerada. Das espécies estudadas como receptoras, malícia e fedegoso foram aquelas em que a germinação das sementes foi afetada em maior ordem de grandeza. Para malícia, concentrações iguais ou superiores a $0,6 \%$ proporcionaram $100 \%$ de inibição da germinação, enquanto para fedegoso esse efeito foi verificado a $0,8 \%$. Para as espécies malva e mata-pasto, embora inibições expressivas tenham sido verificadas, especialmente para concentrações superiores a $0,6 \%$, não foi verificado $100 \%$ de inibição sobre a germinação das sementes (Tabela 4). Quando se considera a inibição mínima de $50 \%$ da germinação como um nível satisfatório para refletir a potencialidade de uma planta como fornecedora de substâncias químicas com atividade alelopática (Dudai et al., 1999), no presente trabalho, apenas na concentração de $0,8 \%$ esse nível foi atingido em todas as espécies. O maior ou menor grau de inibição verificado para concentrações inferiores mostra que a atividade biológica de um aleloquímico depende tanto da concentração como do limite de resposta da espécie receptora. Aparentemente, o limite da inibição não é constante, estando intimamente relacionado à sensibilidade da espécie receptora. Neste trabalho, a sensibilidade das espécies variou na seguinte ordem decrescente: malícia $>$ fedegoso>mata-pasto>malva.

\section{LITERATURA CITADA}

ABRAHIM, D. et al. Effects of four monoterpenes on germination, primary root growth, and mitochondrial respiration of maize. J. Chem. Ecol., v. 26, n. 2, p. 611624, 2000.

ANAYA, A. L. Allelopathy as a tool in the management of biotic resource in agroecosystems. Crit. Rev. Plant Sci., v.18, n.6, p.697-738, 1999.

DURAN; J.M.; TORTOSA, M.E. The effect of mechanical and chemical scarification on germination of charlock (Sinapis arvensis L.) seeds. Seed Sci. Technol., v. 13, n. 1, p. $155-163,1985$.

DUDAI, N. et al. Essencial oils as allelochemicals and their potential use as bioherbicides. J. Chem. Ecol., v. 25, n. 5, p. 1079-1089, 1999.

HARPER, J. R.; BALKE, N. E. Characterization of the inhibition of $\mathrm{k}^{+}$absorption in oat roots by salicylic acid. Plant Physiol., v. 8, n. 6, p. 1349-1353, 1981.
HEISEY, R. M. Identification of an allelopathy compound from Ailanthus altissima (Simaroubaceae) and characterization of its herbicidal activity. Am. J. Bot., v. 83, n. 3, p. 192-2000, 1996.

JUNTILA, O. Seed and embryo germination in S. vulgaris and $S$. reflexa as affected by temperature during seed development. Physiol. Plant., v. 29, p. 264-268, 1976.

KATO-NOGUCHI, H. et al. Allelopathy of oats. I. Assessment of allelopathic potential of extract of oat shoots and identification of an allelochemical. J. Chem. Ecol., v. 20, n. 2, p. 309-314, 1994.

MAGALHÃES, A. C.; FRANCO, C. M. Toxicidade do feijão-de-porco sobre tiririca. Bragantia, v. 21, p.53-57, 1962.

PUTNAM, A. R.; TANG, C. S. Allelopathy: state of the science. In: PUTBNAM, A.R.; TANG, C.S. (Eds.). The science of allelopathy. New York: John Willey \& Sons. 1986. p. 1-19.

REIGOSA, M. J.; SÁNCHEZ-MOREIRAS, A.; GONZÁLES, L. Ecophysiological approach in allelopathy. Crit. Rev. Plant Sci., v. 18, n. 5, p .577-608, 1999.

RICE, E. L. Allelopathy. London: Academic Press, 1984. $422 \mathrm{p}$.

RICE, E. L. Allelopathy. New York: Academic Press, 1979. $353 \mathrm{p}$.

STATISTICAL ANALYSIS SYSTEM - SAS. User's guide. Version 6. 4.ed. North Caroline: 1989. 846 p.

SMITH, A. E. The potential allelopathy characteristics of bitter sneezeweed (Helenium amarum). Weed Sci., v. 37, p. 665-669, 1989.

SOUZA FILHO, A. P. S.; ALVES, S. M. Potencial alelopático de plantas de acapu (Vouacapoua americana): efeitos sobre plantas daninhas de pastagens. Planta Daninha, v. 18, n. 3, p. 435-441, 2000.

SOUZA FILHO, A. P. S.; ALVES, S. M. Alelopatia em ecossistemas de pastagens cultivadas. Belém: EMBRAPACPATU, 1998. 72 p. (EMBRAPA-CPATU. Documentos, 109).

SOUZA FILHO, A. P. S.; DUTRA, S.; SILVA, M. A. M. M. Métodos de superação da dormência de sementes de plantas daninhas de pastagens cultivadas da Amazônia. Planta Daninha, v. 16, n. 1, p. 3-11, 1998.

SOUZA FILHO, A. P. S.; RODRIGUES, L. R. A.; RODRIGUES, T. J. D. Efeitos do potencial alelopático de três leguminosas sobre três invasoras de pastagens. Pesq. Agropec. Bras., v. 32, n. 2, p. 165-170, 1997.

Planta Daninha, Viçosa-MG, v.20, n.3, p.357-364, 2002 
STOWE, L. G. Allelopathy and its influence on the distribution of plant in the Illinois oldfield. J. Ecol., v. 67, p. $1065-1085,1979$.
TAWATA, S.; HONGO, F. Mimosine allelopathy of Leucaena leucocephala. Leucaena Res. Report, v. 6 , p. 479-501, 1987. 